\title{
In the Classroom
}

\section{Progress in Practice: Can Undergraduate Student} Affiliate Groups Survive After the (Re)Energizers Graduate?

BRIAN P. COPPOLA

The University of Michigan

Ann Arbor, MI 48109-1055

bcoppola@umich.edu

Another strategy is contact and communication in a larger forum, so that groups can more effectively learn

from each others' experiences. he collective memory of the work of undergraduate student clubs is often fleeting, perhaps even more so than the memory of some academic faculty committees! Unlike fraternal organizations, with which members still identify long after they leave their student years, undergraduate students in preprofessional clubs more naturally dis-identify with their organizations once they

Individuals involved in curriculum design often introduce new, modified, or applied ideas about instruction that span from classroom methods to philosophies of education. In this series, we examine progress in chemical education that is related to actual practices, and where many recommendations have originated from areas in higher education that exist alongside of and overlap with chemistry. Rather than an exhaustive review, we will select examples, background, and vocabulary that may either invite interested newcomers to explore a different area in their teaching, or provide language and precedent for individuals who wish to contextualize ideas they have developed independently.

—Brian P. Coppola, Series Editor 
graduate and are no longer undergraduates. In addition, these clubs generally lack externally mandated local or national structures, and so they end up tied strongly to the idiosyncrasies of their institutional setting. As the faculty advisor for both the Alpha Chi Sigma chemistry fraternity and the American Chemical Society Student Affiliates (ACS-SA) at my institution, I have observed the relative consistency of the former group and the periodic peaks and troughs of the latter.

Like some of its earlier successful incarnations, the current ("peak") group of ACS-SA at the University of Michigan owes a great deal to the individual students who came in on a "trough" and revived the program. Unlike the earlier incarnations, these students have created some proactive strategies with which they hope to establish a structure and a tradition that will permit the organization to survive after the innovators have graduated. In this way, their problem is the same one we face in curriculum development: how to get innovations to survive the innovator so that we do not end up having to reform "again and again" [1]. The work of these student affiliates contains lessons about allowing newcomers to take ownership, about cooperation and compromise, and about simple enthusiasm and love for the subject. Another strategy is contact and communication in a larger forum, so that groups can more effectively learn from each others' experiences. As a valid example of "progress in practice," I have invited the University of Michigan ACS Student Affiliates to describe their recent efforts in their own words [2], and their work appears elsewhere in this Journal.

The Chemical Educator maintains an open invitation for similar submissions from student groups, especially with an eye to describing transferable strategies.

\section{REFERENCES}

1. Cuban, L. "Reforming Again, Again, and Again” Educational Researcher 1990, 19, 3.

2. Irish, J. M.; Blum, S. A.; Ihrie, R. A. Chem Educator 1997, 2(4): S1430-4171(97) 04133-4. Avail. URL: http//journals.springer-ny.com/chedr. 